\title{
An empirical Overview on the Implementation of Big Results Now Initiative in Tanzania and its Efficacy on Academic Performance in Secondary Schools
}

Michaela Mhagama*

Lecturer, St. Augustine University of Tanzania, Malimbe-Luchelele, Tanzania

DOI: 1 10.36348/jaep.2020.v04i01.001 | Received: 28.12.2019| Accepted: 08.01.2020 | Published: 16.01 .2020

*Corresponding author: Michaela Mhagama

Abstract

In Tanzania, education is conceived as a strategic agent for mindset transformation and for the creation of a welleducated nation, sufficiently equipped with the knowledge needed to competently and competitively solve the development challenges facing the nation. Based on this conviction, the government adapted the Big Results Now Initiative (BRN) from the Malaysian government in 2013 so as to realize its educational goals. The Big Results Now Initiative was aimed at improving students' academic performance by fast-tracking the quality of secondary school education. It focused on delivering defined goals at a predetermined timeline; that is, from 2013 to 2016. This paper provides an empirical overview on the implementation of Big Results Now initiative in Tanzania and its efficacy on students' academic performance in secondary schools. Big Results Now readiness dimensions and rationale is first presented alongside the nexus between implementation and academic performance in secondary schools. The paper concludes that the implementation of Big Results Now Initiative in Tanzania has had some noticeable effects on the academic performance in secondary schools. However, a lot still need to be done in as far as bridging the existing discrepancy between implementation and quality academic performance. It is recommended that the implementation of important educational initiatives like BRN should follow a bottom-up approach- for a sense of ownership and for a desirable attention to detail. Furthermore, the government should not wholly depend on donors to finance the implementation of educational policies and/or initiative but rather engage the local citizenry.

Keywords: Big Results Now, implementation, academic performance, secondary school education.

Copyright @ 2020: This is an open-access article distributed under the terms of the Creative Commons Attribution license which permits unrestricted use, distribution, and reproduction in any medium for non-commercial use (NonCommercial, or CC-BY-NC) provided the original author and sources are credited.

\section{INTRODUCTION}

To urgently address the existing gap between expansions in school enrolments and the unsatisfactory academic performance recorded in the country during the second phase of the Secondary Education Development Programme (SEDP), the government of Tanzania, with support from the World Bank and other donors adapted and modified the Malaysian Big Fast Results model and initiated the Big Results Now (BRN) in 2013 to suit the educational environment in delivering good academic performance. The BRN was introduced as a parallel programme to SEDP, to accelerate and catalyze different development frameworks and/or initiatives towards the achievement of the National Vision 2025 [1,2].
In order to effectively achieve the general objectives of BRN, the Delivery Lab Methodology (DLM) was co-opted in 2013 with seven point's areas aiming at improving the provision of education in secondary schools [3]. The seven key points included: (1) official school ranking; (2) school incentive scheme; (3) school improvement toolkit; (4) Student Teacher Enrichment Programme (STEP); (5) basic facilities construction; (6) capitation grants; and (7) teachers' motivation [4]. Additionally, the DLM set $60 \%, 70 \%$ and $80 \%$ as overall performance target to be achieved by schools in 2013, 2014 and 2015 respectively [3, 5]. Figure-1 shows the summary of BRN transformational vision for the Tanzania education system. 


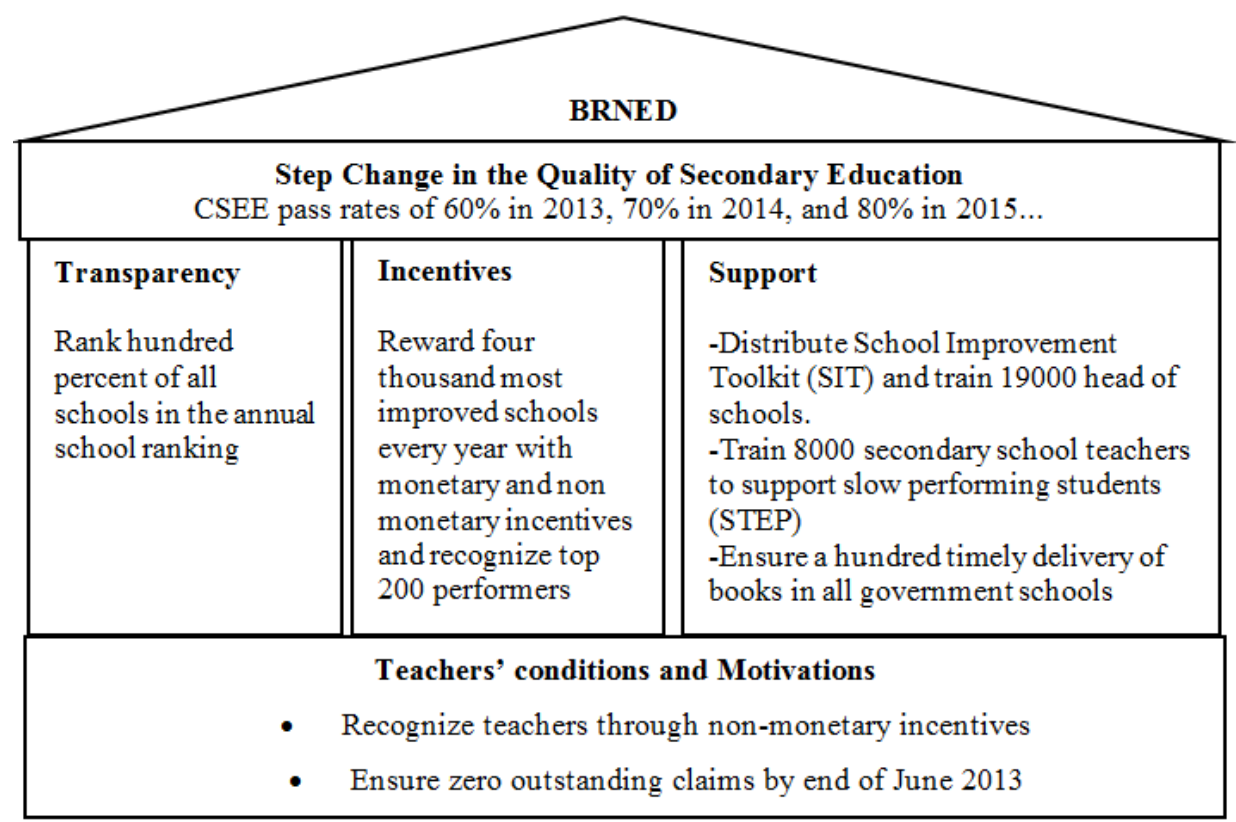

Fig-1: Summary of BRNED transformational vision for the Tanzanian education system Source: URT (2013) [6]; Attfield \&Todd (2017) [7]

The Big Results Now initiative was implemented by MoEVT and Prime Minister's Office, Regional Administration and Local Government (PMORALG). MoEVT was responsible for the overall implementation of the education sector programme in the country; sets standards, trained teachers, and conducted examinations, while PMO-RALG through the Local Government Authorities (LGAs) was responsible for coordinating, providing technical support, and allocating resources. The implementation process was carried out through the Education
Programme for Results (EPforR) whose major objective was to accelerate the implementation of BRN [6]. EPforR' guideline manual was used by MoEVT and PMO-RALG, as well as regional and district officials. In addition, the Education Ministerial Delivery Unit (MDU), President's Delivery Bureau (PDB), and consultants utilized the manual for guidance on workflows, processes, and implementation of BRNED $[6,8]$. Figure- 2 shows the arrangement of the BRNED implementation.

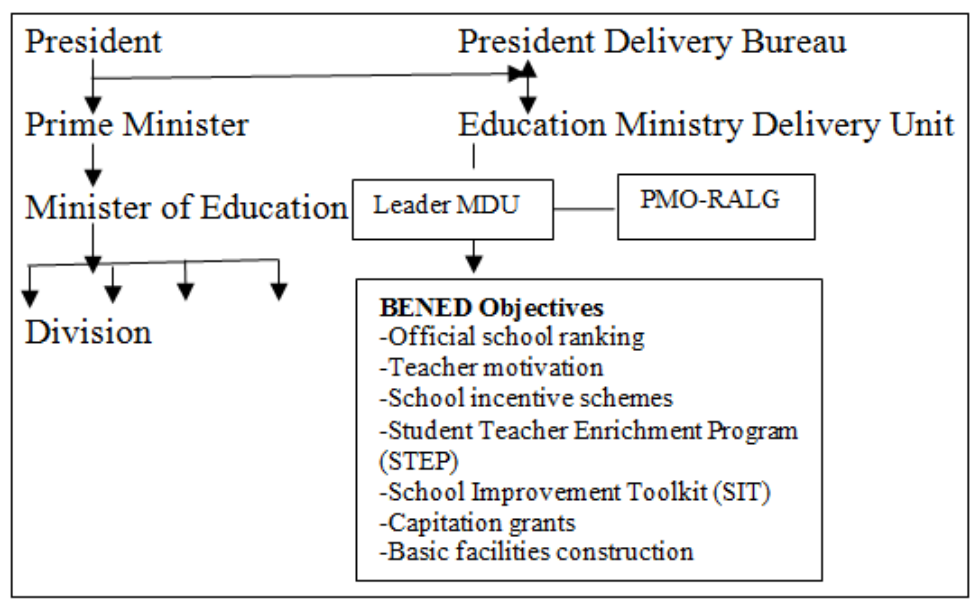

Fig-2: Arrangement of the BRNED implementation

Source: URT (2013) [6]

Moreover, for better implementation of BRNED, the government of Tanzania received monetary support from the Department for International Development (DFID) and other key development partners including SIDA (Swedish International
Development Agency) and World Bank [6]. The monetary contribution towards the implementation of BRN education initiative from these development partners in the budget calendar years 2013-2016 is as presented in Table-1. 
Michaela Mhagama; J Adv Educ Philos, Jan 2020; 4(1): 1-7

Table-1: Monetary Assistance during BRNED from 2013-2016

\begin{tabular}{|l|l|l|l|l|l|}
\hline Donors & \multicolumn{5}{|c|}{ Year } \\
\hline & $\mathbf{2 0 1 3}$ & $\mathbf{2 0 1 4}$ & $\mathbf{2 0 1 5}$ & $\mathbf{2 0 1 6}$ & TOTAL \\
\hline DFID & $£ 14.00 \mathrm{mil}$ & $£ 11.95 \mathrm{mil}$ & $£ 15.90 \mathrm{mil}$ & $£ 13.95 \mathrm{mil}$ & $55.8 \mathrm{mil}$ \\
\hline WB & USD $30.5 \mathrm{mil}$ & USD 29.5 & USD 21.5 & USD 35.5mil & $122 \mathrm{mil}$ \\
\hline SIDA & Kroner 75.2 mil & Kroner 70.6mil & Kroner 72.2 mil & Kroner $82 \mathrm{mil}$ & $300 \mathrm{mil}$ \\
\hline
\end{tabular}

Source: URT (2016) [8]

\section{Implementation of Big Results Now Initiative}

Big Results Now education initiative was implemented in line with stated seven objectives: school ranking, provision of school improvement toolkit, teacher's motivation, and timely release of capitation grants, Student-Teacher Enrichment Program (STEP), school incentive scheme, and construction of basic school facilities [9]. The first objective was the official school ranking for lower secondary schools. This objective was aimed at ranking all schools by examination results every year in order to raise accountability among key stakeholders. The results were to be disseminated to the public through the internet, television, radio, newspapers and other media. It was understood that the ranking system could increase efforts by improving community engagement in education issues. Hence all CSEE result of every school was ranked in bands. There were ten bands; from band1 (highest performing schools with 91-100\% pass rates) to band 10 (lowest performing schools with $1-10 \%$ pass rates). Table-2 shows pass rates in correspondence with GPA and the respective band.

Table-2: Pass rates in relation to BRN bands

\begin{tabular}{|l|l|l|}
\hline Pass Rates \% & GPA & BAND \\
\hline $91-100$ & $1-2$ & Band 1 \\
\hline $81-90$ & $2.1-2.5$ & Band 2 \\
\hline $71-80$ & $2.6-3$ & Band 3 \\
\hline $61-70$ & $3.1-3.5$ & Band 4 \\
\hline $51-60$ & $3.6-4$ & Band 5 \\
\hline $41-50$ & $4.1-4.2$ & Band 6 \\
\hline $31-40$ & $4.3-4.4$ & Band 7 \\
\hline $21-30$ & $4.5-4.6$ & Band 8 \\
\hline $11-20$ & $4.7-4.8$ & Band 9 \\
\hline $1-10$ & $4.9-5$ & Band 10 \\
\hline
\end{tabular}

Key: GPA=Grade Point Average

Source: URT (2013) [9]

The second objective was the provision of school improvement toolkit to heads of schools. It was learned that lack of management training and experience hinders many heads of schools from improving quality in the secondary schools. Gichure [10] on the principle of "no child left behind" advanced that every school must have all teaching and learning materials. For example, each school must have a wellequipped library whereby students and teachers can be able to access information. Thus, availability of teaching materials such as textbooks, chemicals, and laboratory apparatuses, were viewed by BRN as key elements in learning and teaching and thus enhances students' academic performance. As noted by Hoop [11], the education sector in most Sub-Saharan countries faces a shortage of teaching and learning facilities. Similarly, World Bank [12] exposed that urban secondary schools have better textbook supplies and physical facilities than those in rural areas. Usman [13] added that teaching and learning materials are central to the educational process because they facilitate teachers' work and speed up learning on the side of the student. Basing on this understanding, Big Results Now initiative emphasized the availability of relevant teaching and learning materials so as to contribute to students' academic performance.

Therefore, a practical school improvement toolkit that included best practices to manage a school were created and distributed to every head of school. Head of schools were also trained so as to drive quality improvement in their respective schools; 15,525 head teachers and 3,510 school heads received managerial training by September 2013 [9]. Under this objective, guidebooks for BRNED were also provided to the head of schools. The significance of school improvement toolkit was recorded in five major areas: providing orientation materials; providing practical guidance to the heads of schools for school improvement; clarifying the role and core functions of heads of schools; defining accountability of every head of school; and updating of the on-latest changes in policies, teaching and learning information.

According to scholarly writings [1, 14-16], providing capacity building to school leadership is very important to educational achievement. The heads of school are the ones coordinating, harnessing everyone's skills effectively, creating and selling a vision about what is needed to be done in school and creating a good relationship between school and the community around in order to achieve their educational goals which are good student performance [14]. On the other hand, Kombo [16] stated that the basic reason why some schools performed better than others in examinations is differences in management skill especially in organizing human and material resources. Current educational reform places a great emphasis on the effective instructional leadership and management of schools. The main aim of this position is that a wellorganized school environment and well managed provides the preconditions for teaching and learning to take place. Effective school head is generally recognized as the most important characteristic of school administrators [15]. In the same line, Maicibi 
[17] on the school administration relation to academic performance commented that good performance might not be achieved without proper leadership skills in schools. This is because a school can have all the needed teaching and learning facilities and financial resources but it would not be able to perform well academically if the head of the school is unable to manage the resources in the institution. When students are not directed well in the usage of laboratory and library, or if the teachers who guide them in their usage are not competent to show how to use them, these students would not be competent in using the laboratory equipment and chemicals during national examinations.

According to Lezotte [18], instructional leadership is one of the correlates of effective schools. Effective instructional head of schools are proactive and seek help in building team leadership in a school and a culture conducive to learning to take place and teaching professional growth. In the effective school, the head of school, deputy head of school and heads of departments act as instructional leaders and effectively and persistently communicate and implement the educational goals of the country in school, for staff, parents, and students. Lezotte [18] further said that effective instructional leadership is identified through improvement of school results and effectiveness of the school. Also the indicators of schools having effective instructional leaders can be shown through teacher morale to work, satisfaction, teacher self-efficacy and improved students' academic performance. At the same juncture, Lezotte [19] commented that the head of the school is not the sole leader in a school; he/she is a leader of leaders. Hence, he/she must empower teachers and include them in decisions making about the school's instructional goals. Cibulka and Nakayama [20] argue that in order to attain significant changes in school practice; teachers must have a chance to participate in shaping school's goals. Teachers should work together with the head of school to ensure that expectations for student achievement are understood in a school. Johnson [21] suggested that some critical elements are needed to be put in place for a school's leadership to be more effective to create a conducive learning environment for students to learn and teachers to teach.

The third objective of BRNED was the teacher's motivation. This objective aimed at recognizing teachers through non-monetary incentives, ensuring zero outstanding claims by the end of June 2013, and zero unresolved claims. The government allocated Tshs. 25 billion in order to clear all claims within three months $[9,8]$. The fourth objective was to ensure timely release of capitation grants for delivering of books and other teaching and learning materials to all students. It was realized that adequate books and other learning materials were not reaching schools due to process inefficiencies and budgetary constraint. To address this issue, BRNED decided to strengthen the monitoring and delivery systems to ensure successful and timely capitation grant delivery to secondary schools. With this objective, 100 percent timely delivery of books and materials to all students through alternative funding and monitoring was recorded. The resource mobilization was also earmarked at provided Tshs. 158 billion by 2015 for teaching and learning materials to schools through the "education investment levy"' $[22,2]$.

The fifth objective was Student-Teacher Enrichment Program (STEP) which was enabled the government to train 17,000 primary and 8,000 secondary school teachers to support low achieving students. The initiative came into existence when classrooms were overcrowded, and this led to a lack of adequate attention to lower performing students contrary to the target. Also, many teachers lacked the basic skills and tools for effective teaching, such as the scheme of work and lesson plans. Hence, BRNED introduced STEP in secondary schools to enable teachers to identify and support low performing students during the lesson. Also, tests and examinations were to be done frequently so as to determine students who needed the most support and also identifying areas where such students faced more problems. Then, teachers were to teach these specific aspects of the curriculum to these students [9].

The sixth objective was the school incentive scheme through the provision of a monetary incentive to most improved secondary schools and nonmonetary incentives to both improved schools and top performers secondary schools every year. With this objective, MOEVT rewarded 4,000 most improved schools every year from 2013 to 2016 with monetary and nonmonetary incentives and also recognized top 200 performers, starting with the 2013 results. Monetary incentives were between TShs.1, 000,000/= and $5,000,000 /=$ for primary schools and Tshs. $2,000,000 /=$ and $10,000,000 /=$ for secondary schools. Moreover, non-monetary incentives in the form of certificate of achievement were given to a particular school and were issued at a special ceremony published in the media [9]. The seventh objective was the basic facilities construction. This objective enabled the construction of laboratories, libraries and toilets in 1,200 secondary schools by the year 2014 suing the 26 Tshs billion which was released by the government.

The above objectives are within the Tanzania education vision 2025 in which the government seeks to provide equitable quality education and vocational skill to all students [23]. In this aspect, the Tanzanian education system plays a big role in the development of the country through the continuous production of knowledgeable citizens who can solve the challenges. Therefore, in the National Vision 2025, education is taken as an agent for mindset transformational of the 
nation to belong to the middle economic country by 2025.

\section{Academic Performance}

In the conception of the Big Results Now (BRN) initiative, academic performance was conceptualised and understood as school rank based on students' scores in district, regional and national examination results. At an individual level, academic performance referred to scores awarded to students who sat for the district, regional and especially the national examination- Certificate of Secondary Education Examination Certificate of Secondary Education Examinations(CSEE). BRN set performance objectives and those objectives were operationalized in the curriculum and teachers' guides. As opinionated by Galabawa [24], students' academic performance in schools should be dependent upon the curriculum and teachers who is the main instrument for bringing improvement in learning activities. This means that when there is an initiative introduced in the education sector, the success of its implementation depends on the teachers' effective utilization of the set curriculum and guides objectives. This is because, in most cases, the teacher is directly involved in the implementation of the introduced initiatives. Therefore, if the teacher successfully utilizes the subject guides and curriculum, the implementation of the same is likely to be smooth and successful, yet the vice versa is undoubtedly true.

The effectiveness of the implementation of the BRN curriculums and teachers' guide were to be reflected on the students' academic performance or scores in CSEE examinations results. The students pass rates or academic performance during the BRN initiatives were to be compared with the previous academic performances in CSEE examinations before the launch of BRN initiative. Figure-3 indicates the CSEE pass rates countrywide before $\mathrm{BRN}$ education innitiative was implementation from 2009 to 2012. It is this deterioration of CSEE pass rates that caused a national discussion on the reasons for the deteriorating academic performance in Tanzania. In particular, the pass rate for the year 2012 which was $34 \%$, made the Tanzanian Parliament to discuss the results to be regraded. As a result, the debates led the national pass be re-graded from $34 \%$ to $43 \%$ [25].

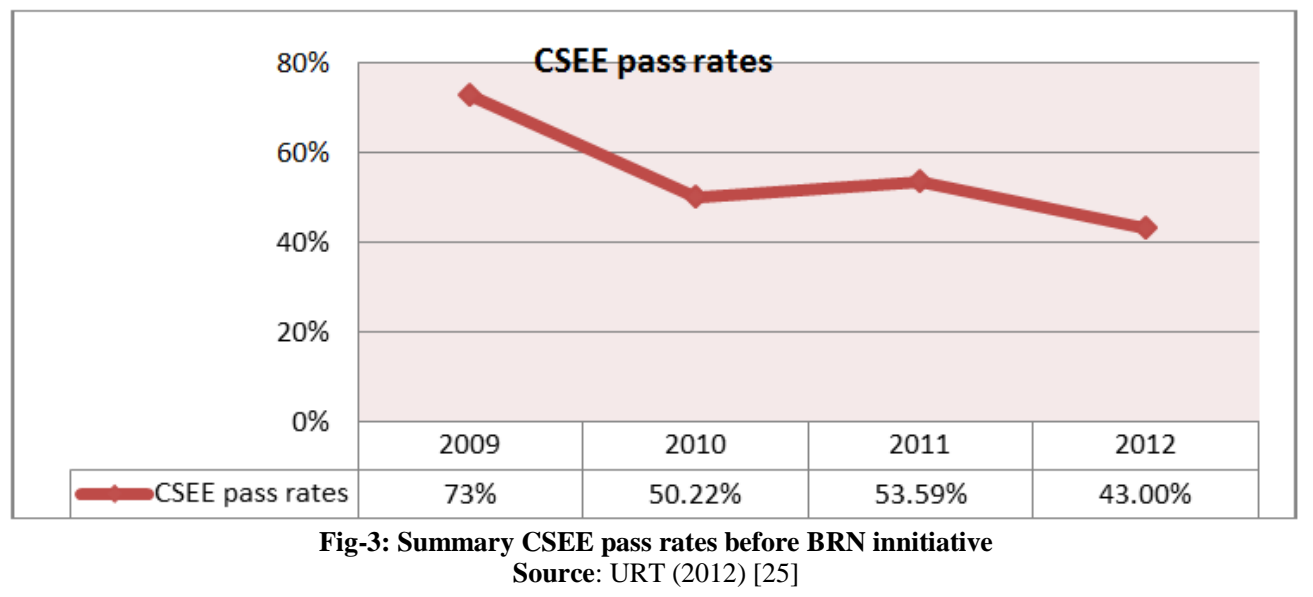

A Form Four candidate who sits for national examinations is awarded divisions one, two, three, four or zero on meeting these conditions: Division one: a candidate passes at least seven and scoring A, B or C in at least five subjects [25]. Division two: a candidate passes at least seven subjects with grade A, B or C in at least four subjects and reaches a total of more than or equal to eighteen points but less than or equal to twenty on points, taking the candidates' best seven subjects. Division Three: a candidate should pass at least seven subjects one of which must be at grade $\mathrm{A}, \mathrm{B}$ or $\mathrm{C}$ or passes at least five subjects two of which must be at grade A, B or C. Reaches a total of more than or equal to twenty two points but less than or equal to twenty five points, taking the candidates' best seven subjects. Division four: a candidate passes at least one subject at grade $\mathrm{A}, \mathrm{B}$ or $\mathrm{C}$, or passes two subjects at $\mathrm{D}$ grade, reaches an aggregate of more than or equal to twentysix points to thirty-three points but less than or equal to thirty-three points, taking the candidate's best seven subjects. Division zero: a candidate does not fulfil the conditions for awards of the divisions one to four [25]. Figure-4 indicates BRNED's set pass rates against CSEE pass rates from 2013 to 2016. 


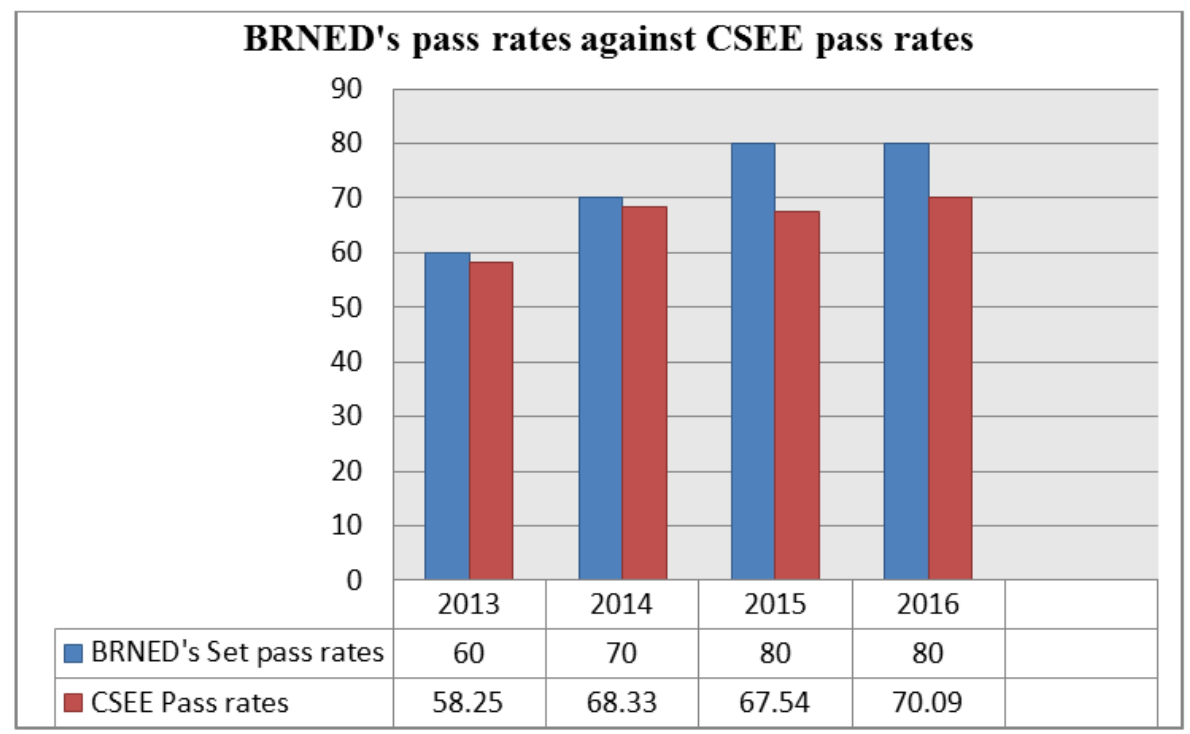

Fig-4: Comparison between BRNED's set pass rates and CSEE Source: URT (2016) [8]

Looking at Figure-4, the CSEE results showed significant improvement during BRNED implementation; even if it was below the BRNED set pass rates. This meant that the results fell behind BRNED targets of $1.75 \%$ in $2013,1.67 \%$ in 2014, $12.46 \%$ in 2015 and $9.1 \%$ in 2016 . Student learning achievement is the state whereby a candidate acquires the expected knowledge and skills that meet the essential standards in education given and its academic performance tested by examination scores. The low academic achievement has been defined as failing to meet the average academic performance in examination scores, as determined by a set cut-off points. In Tanzania, secondary education students sit for CSEE as a summative evaluation for four years [23].

Moreover, under the Tanzania Development Vision 2025, the emphasis of BRN is to ensure that education should be regarded as a significant tool of strategy to bring about changes of thoughts in building the Nation of citizens full of knowledge and skills to solve the country's challenges. However, the CSEE become a necessary tool to capture and measure the trend of performance in secondary education that determines the further level of education [3]. This is supported by Gradstein [26] in a World Bank policy research which presents that the political economy of the developing countries' spends on education, inequality, and growth. In developing countries, it was noted that access to education by poor families was increasingly decreasing in the level of education and therefore the students learning attainment becoming lower in their final examination.

However at a regional conference on Education for all for Sub-Saharan Africa held in Johannesburg 1999, which was attended by respective Ministers of education, representatives of civil society and International development agencies, it was emphasized that for those who were responsible in the education system, were supposed to be more strategic on education issues because what was provided in schools was poor and the curricula often irrelevant to the needs of the learners and economic development. Education planning and management capacity remain largely underdeveloped that is to say only a small number of students are reaching the minimum required competencies [27]. Education and Training Policy [28] stipulates the aims and objectives of education for various levels. For secondary education, the policy was to consolidate and broaden knowledge, skills, and ideas already acquired in primary education, and prepare students for further studies [28].

\section{CONCLUSION}

Big Results Now for education initiative was expected to bring better academic performance of students in government secondary schools. However, from review of literature and taking into consideration the overall BRNED's goals of BRNED, this paper revealed that the examination pass rates were below the expectations. This has been affected by many factors such as limited of funds to buy teaching and learning resources, lack of awareness on the general objectives of BRNED- just to mention a few. Hence, this paper recommends that the Ministry of Education and Science Technology (MOEST) should prepare enough training to stakeholders on any educational programme/initiative being introduced; fund for implementation of the programme should be sourced locally and less from external donors. Furthermore, the implementation process should take a involve all stakeholder using a bottom-up approach- for effective implementation.

\section{REFERENCES}

1. Mchome, E. B. (2016). Assessment of the Factors Affecting Performance of Small and Medium Enterprises in Mtwara Mikindani 
Michaela Mhagama; J Adv Educ Philos, Jan 2020; 4(1): 1-7

Municipality (Doctoral dissertation, The Open University of Tanzania).

2. Nyirenda, M. (2013, August 19). Can we achieve big results now in Education? The Guardian newspaper.

3. URT. (2013). National key areas: Education 2013/2014-2015/2016. Dar es Salaam: Ministry of Education and Vocational Training.

4. Halai, A. (2014). Social justice through mathematics education: Skilling youth for societal participation. In Proceedings of the Joint Meeting of PME (Vol. 38, pp. 67-71).

5. Janus, H., \& Keijzer, N. (2015). Big results now? Emerging lesson from result-based aid in Tanzania (Discussion Paper 4/2015). Bonn: German Development Institute/ Deutsches Institut für Entwi cklungspolitik. Germany.

6. URT. (2013). Tanzania development vision 2025: Big Results Now-Annual report 2013/2014; Roadmap. Dar es Salaam: Ministry of Education and Vocational Training.

7. Attfried, I., \& Todd, R. (2017). Big Results Now! In Tanzanian education: Has the Delivery Approach delivered? Retrieved on $23^{\text {rd }}$ December, 2017.from: http://www.cambed.com/download/file/127/680/big-results-now-intanzanian-education-todd-and-attfield.

8. URT. (2016). Tanzania Big Results Now in Education (BRNED) program for results: Program operations manual-Ministry of education, science, and technology president's office, regional administration, and local government.

9. URT. (2013). Big Results Now! Presentation per annual review meeting: In Julius Nyerere International Convention Centre. Dar es Salaam: Ministry of Education and Vocational Training.

10. Gichure, I. (2010). The "No Child Left Behind" Framework: A way to improve performance in Kenyan schools. Effective schools for 21 st Century in Africa, (pp.207-219) Nairobi: CUEA Press.

11. Hoop, J. (2010). Selective Secondary Education and School Participation in Sub-Saharan Africa. Evidence from Malawi. Tinbergen Institute and $\mathrm{Vu}$ University. Amsterdam.

12. World Bank. (2008). Text Book and School Library Provision in Secondary education in SubSaharan Africa. Washington, D. C: African Region Human Department.

13. Usman, A. (2007). The Relevant Material Resources to the Teaching and Leaning of Arabic and Islamic Studies. An Encyclopedia of the Arts, 7(1):47-52.

14. Gaiti, M. (2010). School-Community Partnership: Components, Areas of Conflict and Strategies for
Effective Partnerships. Effective Schools for $21^{\text {st }}$ Century in Africa, (pp.4-16) Nairobi: Press.

15. Hoy, A. W., \& Hoy, W. K. (2009). Instructional leadership: A research-based guide to learning in schools. Boston, MA: Allyn and Bacon.

16. Kombo, D. K. (1988). Causes of poor performance in Harambee secondary schools in Kathiani Division. Unpublished. Masters of Education Thesis, Kenyatta University Nairobi.

17. Maicibi, N. A. (2005). Pertinent issues in management: Human Resource and Educational Management, $\left(1^{\text {st }}\right.$ ed), Net Media Publishers, Kampala.

18. Lezotte, L. W. (2010). What effective schools do: Re-envisioning the correlates. Indianapolis, IN: Solution Tree.

19. Lezotte, L. (1991). Correlates of effective schools: The first and second generation. Okemos, MI: Effective Schools Products, Ltd.

20. Cibulka, J., \& Nakayama, M. (2000). Practitioners' Guide to Learning Communities. Creation of High-Performance Schools through Organizational and Individual Learning.

21. Johnston, C. (1997). Leadership and the learning organization in self-managing schools. Unpublished Doctoral Thesis. University of Melbourne. Melbourne.

22. Adeogun, A. A. (2001). The principal and the financial management of public secondary schools in Osun State. Journal of Educational System and Development, 5(1):1-10.

23. URT. (2010). Education Sector Development Programme: Secondary Education Development Plan (July 2010-June 2015). Dar es Salaam: Ministry of Education and Vocational Training.

24. Galabawa, J. C. (2001). Perspectives in educational management and administrative. Dar es Salaam: KAD Associations.

25. URT. (2012). Poverty and Human Development Report 2011, Research and Analysis Working Group MKUKUTA Monitoring System. Ministry of Finance, Mkuki na Nyota Publishers, Dar es Salaam.

26. Gradstein, N. (2003). The Political Economy of public spending on education, inequality, and growth. World Bank Policy Research Paper, 3:62 70.

27. UNESCO. (2004). Education for all fast-track initiative (FTI: Status report, prepared for the education for all fast-track initiative annual meeting). UNESCO Press, Paris.

28. URT. (1995). Education and Training Policy. Dar es Salaam: Ministry of Education and Culture. 